Running head: Moral foundations questionnaire, revised

\title{
Reanalyzing the factor structure of the Moral Foundations Questionnaire
}

Craig A. Harper* \& Darren Rhodes

Nottingham Trent University (UK)

* Correspondence concerning this article should be addressed to:

Dr. Craig Harper

Department of Psychology, Nottingham Trent University

50 Shakespeare Street, Nottingham, NG1 4FQ, UK

Email: craigaharper19@ gmail.com Tel.: +44 (0)115848 4718 Twitter: @CraigHarper19

\section{Open Science Practices}

Data for both studies are available at: https://osf.io/nwpb6/ 


\begin{abstract}
The moral foundations theory (MFT) is an influential multifactorial model that posits how decision-making in the moral context originates from a set of six intuitive moral foundations: care, fairness, authority, loyalty, purity, and liberty. The established measure of these foundations - the Moral Foundations Questionnaire (MFQ) - has been used extensively in a range of empirical projects. However, recent analyses of its factor structure and the internal consistency of the each of the foundation clusters have called its validity into question. In this paper, data from a large sample of British voters was used to re-examine the factor structure of the MFQ. As opposed to a six-factor structure, only three meaningful clusters emerged in an exploratory principal factors analysis (Study 1; $N=428$ ): traditionalism, compassion, and liberty. This structure was broadly confirmed in an independent sample (Study 2; $N=322$ ). Concurrent validity was established via correlations with measures of 'social change' and 'systemic inequality' insecurities (Study 1) and voting behavior and preferences (Study 2). Significant differences on each of the three factors of the revised MFQ (MFQ-r) were observed between the voters of different political parties (Study 1) and sides of the Brexit issue (Study 2). Implications for moral foundations theory and its measurement are discussed.
\end{abstract}

Keywords: moral foundations theory; measurement; ideology; politics; moral foundations questionnaire 
Reanalyzing the factor structure of the Moral Foundations Questionnaire

\section{Introduction}

Moral foundations theory (MFT; Haidt \& Joseph, 2004) is a theoretical framework of moral decision-making. It has been applied to a range of areas of study, such as selfidentified political ideology (Clifford, 2017; Franks \& Scherr, 2015; Graham et al., 2009; 2012; Haidt \& Graham, 2007; Iyer et al., 2012; Nilsson \& Erlandsson, 2015), specific sociopolitical attitudes and behaviors (Barnett et al., 2018; Dickinson et al., 2016; Low \& Wui, 2016), public health messaging (Christie et al., 2019), judgments of crime (Harper \& Harris, 2017; Silver \& Silver, 2017; Vaughan et al., 2019), and perceptions of leadership and business ethics (e.g., Egorov et al., 2019). The theory is grounded in cultural and evolutionary psychology and anthropology, and is designed to provide a universal conceptualization of the human moral landscape (Doğtuyol et al., 2019). Three core principles underpin the MFT (see Haidt, 2012), namely that:

1. Moral judgments are made using intuitive processes, with our verbal explanations representing post-hoc justifications of choices made non-consciously and instinctively (for a theoretical conceptualization of this process, see Haidt, 2001). This first premise stems from seminal work by Tversky \& Kahneman (1974), who argued how heuristic-based intuitive cognition drives decision-making.

2. Morality is a multi-dimensional construct comprised of a discrete set of moral foundations. These foundations represent the core moral domains within which a given stimulus or scenario is appraised

3. The relative importance attributed to respective moral dimensions is variable across the population.

The multidimensionality of morality within the context of the MFT was postulated by Haidt and Joseph (2004), who suggested four such moral intuitions: preventing suffering (care), respecting hierarchies (authority), acting reciprocally (fairness), and behaving purely (purity). These formed the basis of the first draft of the MFT, with Haidt and Graham (2007) advocating for a fifth domain: affinity to one's group (loyalty). This led to a theory comprised of five moral foundations, defined as the core innate domains of moral decision-making (Haidt, 2012). In the ensuing years, Iyer et al. (2012) posited that a desire for autonomy and freedom (liberty) could also be classified as a moral domain, bringing the number of moral 
foundations to six. It is worth noting here that MFT is not the only theoretical account of morality within the psychological literature. Some researchers advocate single-factor conceptualizations of morality, with harm being the most salient factor (Gray et al., 2014). Alternatively, Curry's theory of 'morality-as-cooperation' suggests a seven-factor model of morality, based on seven different types of cooperation (Curry et al., 2019). However, the most commonly cited and studied approach to understanding human morality is the MFT, hence our focus on this framework here.

The MFT has perhaps been most influential within the political domain. Here, multiple research teams have consistently reported differences in the endorsement of the moral foundations between ideological and partisan groups from across the political spectrum (for a popular review, see Haidt, 2012). Across cultures, liberals are said to endorse a 'two-channel' view of morality, with the focus in these individuals being on caring for the most vulnerable in society and acting fairly or equitably, whereas conservatives value all five of the original moral foundations at around the same level (see Graham et al., 2009; 2011; 2012; Johnson et al., 2017; Kugler et al., 2014; Rempala et al., 2016). These high-level ideological differences are also observable in self-reported voting preferences, with the leftward voting being predicted by higher levels of endorsement of 'individualizing' (care and fairness) foundations, and rightward voting by endorsement of 'binding' (authority, loyalty, and purity) foundations (Franks \& Scherr, 2015; Milesi, 2017). Among self-identified libertarians, Iyer et al. (2012) reported levels of endorsement of the care and fairness foundations that were more consistent with ideological liberals, but with a heavy focus also being placed on themes related to economic and lifestyle liberty. Even on these two liberty dimensions, an asymmetry between partisan liberals and conservatives was observed, with conservatives endorsing economic liberty (e.g., property rights) more than lifestyle liberty (e.g., opposition to culturally-enforced social norms), with liberals showing the opposite trend (Iyer et al., 2012).

These relationships between moral foundations and political attitudes do not necessarily reflect an underlying causal mechanism. Instead, these associations may be reflective of the framing of the items on the Moral Foundations Questionnaire (MFQ). In an example of this, Voelkel and Brandt (2019) demonstrated how manipulating the targets of moral behavior changed the relationships between some moral foundations (e.g., loyalty) with political ideology. That is, instead of asking about loyalty to one's country (a conservative instinct), Voelkel and Brandt (2019) found high rates of liberal 'loyalty' endorsement by asking about loyalty to one's labor union. Findings such as these led Hatemi et al. (2019) to suggest that 
"moral foundations do not cause or meaningfully predict political ideology. Political orientations are more stable across time than moral foundations, and moral foundations are more likely a product of political orientations rather than the reverse" (pp. 803-804).

Construct measurement within the context of the MFT usually takes the form of the Moral Foundations Questionnaire (MFQ; Graham et al., 2009). This is a 32-item scale (with only 30 of these being scored because of two 'catch' questions designed to identify inattentive or random responding). These items are divided into two sections. In the first section, respondents state how relevant a collection of issues are to them when making a moral decision. Examples of such issues include 'Whether or not someone suffered emotionally' (mapping on to the care foundation) and 'Whether or not someone did something disgusting' (mapping on to the purity foundation). The second section of the MFQ asks respondents to rate their level of agreement with a range of moral statements, such as 'Justice is the most important requirement for a society' (mapping on to the fairness foundation) and 'It is more important to be a team player than to express oneself' (mapping on to the loyalty foundation). Scoring occurs by averaging the responses to each of the six items per moral foundation.

In spite of the MFQ continuing to be used as the gold-standard measure of moral foundations, the scale itself has come in for criticism. For example, recent confirmatory factor analyses have found only reasonable levels of model fit when using the default fivefoundation model (comparative fit indices [CFIs] $<0.90$; root mean square error of approximation [RMSEA] > 0.08; Iurino \& Saucier, 2020; Kim et al., 2012; Kivikangas et al., 2017; Nilsson \& Erlandsson, 2015; Yilmaz et al., 2016), with fit indices only improving to acceptable standards upon the removal of low-loading items (Nilsson \& Erlandsson, 2015). In a large-scale analysis of measurement invariance in the 20-item short form of the MFQ, Iurino and Saucier (2020) found that the five-factor model did not translate well across 27 countries from nine global areas (though see Brandt et al. [2020] for data suggesting that a lack of invariance does not impact the conclusions drawn in relation to ideological differences). They also suggested that the MFQ (or, at least, the short form of the measure) may only measure two factors related to harm and social order. These correspond to the two higher order 'individualizing' and 'binding' foundation clusters that have been theoretically suggested in prior work (Franks \& Scherr, 2015; Milesi, 2017). These findings cast doubt on the GENERALISABILITY of MFT's proposed five-factor structure. Although there is little reason to doubt the translatability of this analysis to the full MFQ (for evidence of the crosscultural stability of the MFQ, see Doğruyol et al., 2019), no work has been conducted that 
seeks to re-examine the dimensionality of the full MFQ alongside the newer liberty items from Iyer et al. (2012).

Similar issues with fit have also been reported at the individual foundation level (Davis et al., 2017). While these questionable fit indices may be reflective of a conceptual difficulty in operationalizing and quantifying moral intuitions in a more general sense, they do call into question the utility of the MFQ in its current five-factor form. Further, among studies that have not explicitly tested the fit of the five-factor model of the MFQ, the internal consistency of each of the moral foundations (i.e., Cronbach's alpha coefficients) have produced poor coefficients: care foundation $\alpha=.50-.62$ (Graham et al., 2009; Harper \& Hogue, 2019); fairness foundation $\alpha=.39-.69$ (Graham et al., 2009; 2011; 2012; Harper \& Hogue, 2019); authority foundation $\alpha=.39-.64$ (Graham et al., 2009); loyalty foundation $\alpha=.24-.58$ (Graham et al., 2009; 2012); purity foundation $\alpha=.58$ (Graham et al., 2009).

As alluded above, previous work into the MFT's proposed five-factor model tended to support a two-factor liberal-conservative (usually referred to as 'binding' and 'individualizing' moral domains, respectively; Franks \& Scherr, 2015; Graham et al., 2009; 2011; 2012; Johnson et al., 2017; Kugler et al., 2014; Milesi, 2017; Rempala et al., 2016). Here, we replicate that previous research and extend it to include, for the first time, a third politico-moral domain factor representing libertarianism by integrating Iyer et al.'s (2012) liberty items into the MFQ. The aforementioned measurement issues provide a clear rationale for taking a different approach to understanding the factor structure of the MFQ. In this paper, a reanalysis of this factor structure is undertaken. Specifically, instead of attempting to confirm the predefined default five- or six-factor structure, new parallel and exploratory factor analyses provide a new look at the factor structure of the MFQ, taking into account the liberty items published by Iyer et al. (2012). A reanalyzed structure is also confirmed in an independent sample. Concurrent validity of a new factor structure is provided, alongside information about how such a reframing of the MFQ relates to the British political context.

\section{Study 1}

In Study 1 we aim to achieve two goals. First, we re-analyze the factor structure of the MFQ after embedding Iyer et al.’s (2012) liberty-related items. Second, we offer some evidence of the concurrent validity of the revised structure in an exploratory analysis of its associations with sociopolitical constructs and voting behavior. This was an important additional process owing to the known links between MFT and political attitudes and voting 
behavior (Franks \& Scherr, 2015; Graham et al., 2009; 2011; 2012; Johnson et al., 2017; Kugler et al., 2014; Milesi, 2017; Rempala et al., 2016).

\section{Methods}

\section{Participants}

Participants in this study were drawn from a broader project looking at the psychological underpinnings of political behavior in the UK, specifically in relation to the Brexit vote. This previous work was designed to understand the various predictors of voting in the 2016 referendum of EU membership, and is reported in Harper and Hogue (2019). The sample used here are all those participants who fully completed the MFQ (plus liberty items from Iyer et al., 2012). As such, 428 participants ( $70 \%$ male; $M_{\text {age }}=33.54$ years, $S D=14.13$ ) are included in the analyses that follow. Most were educated to degree level (60\%) and intended to vote 'Remain' prior to the EU referendum in June 2016 (61\%). In terms of voting preferences at the previous UK general election in 2015, participants tended to favor leftleaning parties, such as Labour (32\%), the Liberal Democrats (11\%), or the Green Party $(11 \%)$. However, there was representation from the right-hand side of the political spectrum, with support for the Conservatives (15\%), UKIP (independence party; 11\%), and 'others' (e.g., smaller fringe parties or independent candidates; $5 \%$ ). Around $13 \%$ of the sample did not vote in the 2015 general election.

For the broader project, a varied sampling strategy was employed in order to attract a politically diverse sample. This included posting study advertisements on general community groups on Facebook (encompassing several regions of the UK, including both urban and rural settings), the use of Twitter using \#EUref and \#Brexit, and placing study announcements on Reddit forums for each of the five main political parties in the UK (the Conservatives, Labour, the Liberal Democrats, the Green Party, and UKIP), as well as fora that were specifically devoted to discussions of British politics and the EU referendum. All advertisements encouraged viewers to share the link in order to facilitate the collection of a large and varied sample.

\section{Measures}

Demographic questionnaire. Participants provided personal information about their sex, age, level of education (pre-/post-degree), party vote at the last general election, planned vote in the EU referendum, and their general political views (measured using an 11-point scale anchored from -5 to +5 ; negative scores $=$ liberal, positive scores $=$ conservative) . 
Moral Foundations Questionnaire. The 32-item MFQ (Graham et al., 2009) was administered to examine participants' endorsement of each of established moral foundations (care, fairness, authority, loyalty, and purity). Each foundation is assessed using six items, with these being scored using a six-point Likert scale. Two 'catch' questions are also included to check that participants are paying attention to the scale when responding, and to encourage participants to use the extremes of the Likert scales. Average foundation scores and Cronbach's alpha coefficients for each foundation (see Table 1) were computed using the syntax posted by the scale authors at MoralFoundations.org. The original MFQ was accompanied by Iyer et al.'s (2012) nine items for measuring endorsement of the liberty foundation. These items were randomly placed (within their respective half of the MFQ) among the other items in order to avoid biased responding, with all items then being randomized for each participant. As demonstrated in Table 1, the internal consistency across the foundations was variable, though this was slightly better within the present sample than in previous research using the MFQ.

Table 1. Average moral foundation scores and internal consistency of the original form MFQ

\begin{tabular}{llcc}
\hline Foundation & Example item & $\boldsymbol{M}(\boldsymbol{S D})$ & $\boldsymbol{\alpha}$ \\
\hline Care & $\begin{array}{l}\text { "Compassion for those who are suffering is the } \\
\text { most crucial virtue" }\end{array}$ & $4.36(0.81)$ & 0.64 \\
Fairness & $\begin{array}{l}\text { "I think it's morally wrong that rich children inherit } \\
\text { a lot of money while poor children inherit nothing" }\end{array}$ & $4.63(0.71)$ & 0.63 \\
Authority & $\begin{array}{l}\text { "Respect for authority is something all children } \\
\text { need to learn" }\end{array}$ & $3.39(0.98)$ & 0.76 \\
Loyalty & $\begin{array}{l}\text { "People should be loyal to their family members, } \\
\text { even when they have done something wrong" }\end{array}$ & $3.16(0.90)$ & 0.74 \\
Purity & $\begin{array}{l}\text { "I would call some acts wrong on the grounds that } \\
\text { they are unnatural" }\end{array}$ & $2.64(1.05)$ & 0.81 \\
Liberty & $\begin{array}{l}\text { "The government interferes far too much in our } \\
\text { everyday lives" }\end{array}$ & $3.94(0.89)$ & 0.73 \\
\hline
\end{tabular}

Ontological Insecurities Scale. We used the 14-item two-factor Ontological Insecurities Scale (OIS; Harper \& Hogue, 2017) in order to examine insecurities about 'social change' (e.g., "The pace of social change is too quick"; $\alpha=0.94$ ) and 'systemic inequality' (e.g., "We live in a fair society"; $\alpha=0.65$ ). Each item is rated on a six-point Likert scale, anchored from 1 (strongly disagree) to 6 (strongly agree). Average scores are computed for each subscale, with high scores being indicative of greater insecurity. This measure was used as it offers a less politically-explicit measure of themes that, according to Harper \& Hogue's 
(2017) development data, are related to right-wing authoritarianism ( $r$ with 'social change' insecurities $=0.81, p<.001)$ and having a social dominance orientation ( $r$ with 'systemic inequality' insecurities $=-0.35, p<.01$ ).

\section{Procedure}

Advertisements containing a link to a survey looking at 'British political attitudes' were placed in the various locations online, as indicated previously. Those who were interested in taking part clicked on the survey weblink (hosted by Qualtrics) and were presented with an overview of the project. Explicit informed consent was indicated by participants clicking a confirmation button. All participants first provided their demographic information, before completing the MFQ and OIS in a randomized order. This procedure received ethical approval from a departmental review committee prior to data collection, and conformed to British Psychological Society ethical standards.

\section{Results}

An anonymized version of the dataset (in .omv format) is available for download at https://osf.io/nwpb6/?view_only=dc6886f6192b47cabf09dc99b04d5cce.

\section{Parallel and Exploratory Factor Analysis}

A parallel analysis was run on the data for the 41-item MFQ (the original 32 items, plus nine liberty items) to determine the likely number of factors underpinning the data. This analysis was performed using syntax provided by O'Connor (2000), which takes multiple simulations of a principal components analysis (PCA) to calculate mean component eigenvalues. If an observed eigenvalue (from the actual dataset) of a component exceeds the size of the $95^{\text {th }}$ percentile of the eigenvalue distribution (from the simulations), this represents a statistically meaningful component. As demonstrated in Figure 1, this parallel analysis indicated that five factors underpinned the data. 


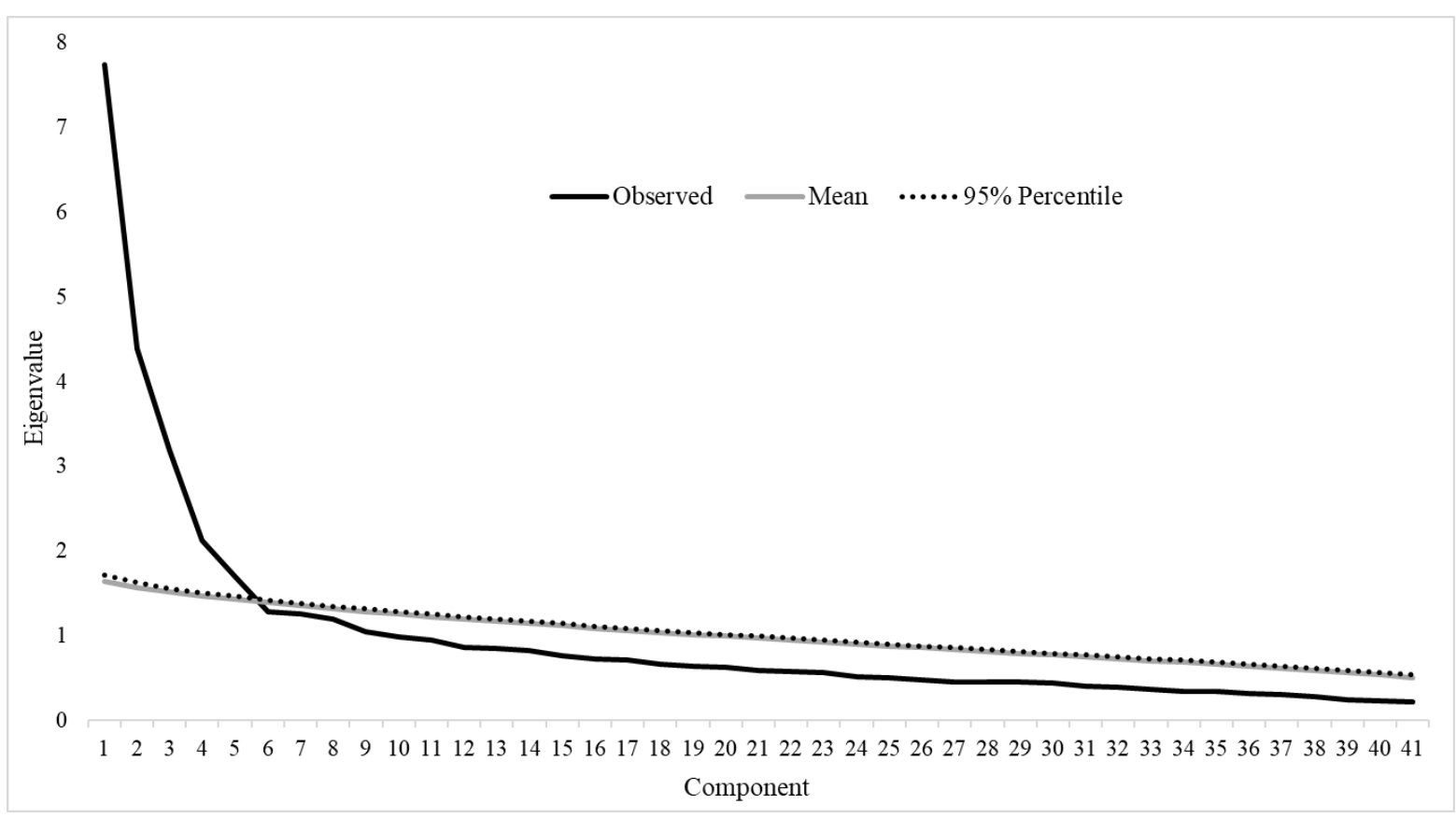

Figure 1. Parallel analysis of the 41-item MFQ

Owing to the parallel analysis output, an exploratory factor analysis (using maximum likelihood extraction with varimax rotation) was run with the instruction to extract five factors. The sample size of 428 is suitable for this type of analysis, exceeding the fiveobservations-per-item rule of thumb (Osborne et al., 2008). Further, the Kaiser-Meyer-Olkin measure of sampling adequacy $(0.87)$ and Bartlett's test for sphericity $\left(\chi^{2}(741)=6410, p<\right.$ .001) suggested that the data were suitable for testing dimensionality.

The results of the exploratory factor analysis are presented in Table 2. As can be seen, this analysis led to three psychometrically strong factors, a fourth containing only two items that cross-loaded onto the first factor, and a fifth factor consisting of only three items. As such, a three-factor structure was accepted for further interrogation. In order to retain as many items as possible while still producing a measure that was not skewed in favor of any particular factor, the top-loading ten items of the first factor were retained. Initial analyses demonstrated acceptable levels of model fit $\left(\mathrm{RMSEA}=0.05, \mathrm{TLI}=0.85, \chi^{2}(556)=1194, p<\right.$ $.001)$. It is important to highlight that this three-factor structure is inconsistent with the parallel analysis. However, the need to develop a parsimonious and conceptually coherent measure made this deviation from the parallel analysis necessary.

The first factor was labelled 'Traditionalism' and was comprised of items such as "Respect for authority is something all children need to learn" and "Whether or not someone conformed to the traditions of society". This cluster of items relate to the binding principles 
of loyalty to one's ingroup and the development of social norms (Cronbach's $\alpha=0.88$, McDonald's $\omega=0.88)$.

The second factor was labelled 'Compassion' and contained items such as "Whether or not someone cared for someone weak or vulnerable" and "Whether or not someone suffered emotionally". This cluster pertains to the individualizing principles of respect for individuality, fair treatment, and the elimination of judgments based on established social hierarchy or group membership (Cronbach's $\alpha=0.76$, McDonald's $\omega=0.77$ ).

The third factor was labelled 'Liberty' and contained items such as "The government interferes far too much in our everyday lives" and "People who are successful in business have a right to enjoy their wealth as they see fit". This collection of items exclusively came from Iyer et al.'s (2012) liberty questionnaire, suggesting that these items related to a distinct orientation toward individuality and freedom from external control (Cronbach's $\alpha=0.72$, McDonald's $\omega=0.73$ ). 
Table 2. Item loadings within the exploratory factor analysis of the 41-item MFQ

\begin{tabular}{|c|c|c|c|c|c|}
\hline \multirow[b]{2}{*}{ Item } & \multicolumn{5}{|c|}{$\underline{\text { Factor }}$} \\
\hline & 1 & 2 & 3 & 4 & 5 \\
\hline$\overline{\text { Whether or not someone showed a lack of respect for authority }}$ & $\underline{0.744}$ & 0.081 & -0.076 & 0.142 & 0.023 \\
\hline Respect for authority is something all children need to learn & $\overline{\mathbf{0 . 7 4 3}}$ & -0.120 & 0.015 & 0.078 & 0.160 \\
\hline People should not do things that are disgusting, even if no one is harmed & $\underline{0.673}$ & -0.144 & -0.077 & 0.105 & 0.367 \\
\hline Whether or not someone violated standards of purity and decency & $\underline{0.653}$ & 0.091 & -0.061 & 0.226 & 0.087 \\
\hline Whether or not someone did something disgusting & $\underline{0.645}$ & 0.233 & -0.024 & 0.191 & 0.103 \\
\hline Whether or not someone conformed to the traditions of society & $\underline{0.618}$ & -0.014 & 0.003 & $\underline{0.504}$ & -0.179 \\
\hline I would call some acts wrong on the grounds that they are unnatural & $\underline{0.580}$ & -0.159 & -0.029 & 0.228 & 0.162 \\
\hline Chastity is an important and valuable virtue & $\overline{0.512}$ & -0.141 & 0.053 & 0.269 & 0.061 \\
\hline Whether or not private property was respected & $\underline{0.498}$ & 0.305 & 0.305 & -0.048 & -0.287 \\
\hline Whether or not someone's action showed love for his or her country & $\underline{0.492}$ & -0.006 & 0.169 & $\underline{0.479}$ & -0.064 \\
\hline $\begin{array}{l}\text { If I were a soldier and disagreed with my commanding officer's orders, I would obey anyway } \\
\text { because that is my duty }\end{array}$ & $\underline{0.490}$ & -0.149 & 0.113 & 0.126 & 0.009 \\
\hline Whether or not an action caused chaos or disorder & $\underline{0.487}$ & 0.297 & 0.008 & 0.073 & -0.096 \\
\hline I am proud of my country’s history & $\underline{0.476}$ & -0.203 & 0.311 & 0.150 & -0.147 \\
\hline $\begin{array}{l}\text { I think it's morally wrong that rich children inherit a lot of money while poor children inherit } \\
\text { nothing }\end{array}$ & $\underline{-0.413}$ & 0.293 & -0.233 & 0.130 & 0.276 \\
\hline Men and women each have different roles to play in society & 0.347 & -0.240 & 0.156 & 0.178 & -0.138 \\
\hline Whether or not someone acted unfairly & -0.013 & $\underline{0.669}$ & -0.004 & 0.059 & 0.045 \\
\hline Whether or not someone was cruel & 0.185 & $\underline{0.653}$ & -0.073 & 0.043 & 0.090 \\
\hline Whether or not someone was denied his or her rights & -0.170 & $\underline{0.650}$ & 0.097 & -0.149 & 0.049 \\
\hline Whether or not some people were treated differently than others & -0.082 & $\underline{0.552}$ & -0.040 & -0.122 & 0.235 \\
\hline Whether or not someone cared for someone weak or vulnerable & -0.040 & $\underline{0.501}$ & -0.078 & 0.288 & 0.249 \\
\hline Whether or not someone suffered emotionally & 0.027 & $\underline{0.419}$ & -0.202 & 0.084 & 0.323 \\
\hline Whether or not everyone was free to do as they wanted & -0.089 & $\overline{0.388}$ & 0.352 & 0.008 & -0.067 \\
\hline
\end{tabular}




\begin{tabular}{|c|c|c|c|c|c|}
\hline \multirow[b]{2}{*}{ Item } & \multicolumn{5}{|c|}{$\underline{\text { Factor }}$} \\
\hline & 1 & 2 & 3 & 4 & 5 \\
\hline $\begin{array}{l}\text { Society works best when it lets individuals take responsibility for their own lives without } \\
\text { telling them what to do }\end{array}$ & -0.011 & -0.088 & $\underline{\mathbf{0 . 7 4 4}}$ & 0.174 & 0.024 \\
\hline $\begin{array}{l}\text { I think everyone should be free to do as they choose, so long as they don't infringe upon the } \\
\text { equal freedoms of others }\end{array}$ & -0.205 & 0.167 & $\underline{0.670}$ & 0.009 & 0.097 \\
\hline People who are successful in business have a right to enjoy their wealth as they see fit & $\underline{0.485}$ & -0.187 & $\underline{0.530}$ & -0.052 & -0.095 \\
\hline The government interferes far too much in our everyday lives & 0.177 & -0.083 & $\underline{0.482}$ & 0.144 & -0.035 \\
\hline $\begin{array}{l}\text { Property owners should be allowed to develop their land or build their homes in any way they } \\
\text { choose, as long as they don't endanger their neighbours }\end{array}$ & 0.110 & -0.168 & $\underline{\mathbf{0 . 4 3 9}}$ & 0.027 & 0.073 \\
\hline $\begin{array}{l}\text { The government should do more to advance the common good, even if that means limiting the } \\
\text { freedom and choices of individuals }\end{array}$ & -0.015 & -0.023 & $\underline{-0.407}$ & 0.053 & 0.203 \\
\hline People should be free to decide what group norms or traditions they themselves want to follow & -0.166 & 0.212 & 0.392 & -0.132 & 0.231 \\
\hline Justice is the most important requirement for a society & 0.241 & 0.114 & 0.251 & 0.125 & 0.242 \\
\hline Whether or not someone showed a lack of loyalty & 0.389 & 0.157 & 0.124 & $\underline{0.648}$ & -0.078 \\
\hline Whether or not someone did something to betray his or her group & 0.353 & 0.181 & 0.114 & $\underline{0.632}$ & -0.098 \\
\hline People should be loyal to their family members, even when they have done something wrong & 0.274 & -0.126 & 0.157 & 0.391 & 0.141 \\
\hline Whether or not someone acted in a way that God would approve of & 0.311 & -0.122 & -0.086 & 0.337 & 0.069 \\
\hline It is more important to be a team player than to express oneself & 0.241 & -0.054 & -0.101 & 0.243 & 0.236 \\
\hline Compassion for those who are suffering is the most crucial virtue & -0.087 & 0.391 & -0.147 & -0.016 & $\underline{0.526}$ \\
\hline It can never be right to kill a human being & 0.090 & 0.075 & -0.024 & -0.080 & $\underline{0.480}$ \\
\hline $\begin{array}{l}\text { When the government makes laws, the number one principle should be ensuring that everyone } \\
\text { is treated fairly }\end{array}$ & -0.079 & 0.323 & 0.121 & -0.140 & $\underline{0.434}$ \\
\hline One of the worst things a person could do is hurt a defenseless animal & 0.114 & 0.081 & 0.085 & 0.080 & 0.353 \\
\hline
\end{tabular}

Note. Significantly loading items (>.40; Field, 2018) are underlined. Retained items in the preliminary scale are presented in bold typeface. 


\section{Concurrent Validity of the Revised MFQ}

To test the concurrent validity of the revised MFQ (the 'MFQ-r'), the three factors were correlated against each other, as well as against the age and political orientation demographic variables, and the 'social change' and 'systemic inequality' OIS factors (Table 3).

Table 3. Zero-order correlations demonstrating concurrent validity of the MFQ-r

\begin{tabular}{lccccccc}
\hline & 1 & 2 & 3 & 4 & 5 & 6 & 7 \\
\hline 1. MFQ-r 'Traditionalism' & - & -.05 & $.25^{* * *}$ & $.29^{* * *}$ & $.58^{* * *}$ & $.58^{* * * *}$ & $-.29^{* * *}$ \\
2. MFQ-r 'Compassion' & & - & $-.15^{* *}$ & -.03 & $-.36^{* * * *}$ & $-.34^{* * *}$ & $.29^{* * * *}$ \\
3. MFQ-r 'Liberty' & & & - & .03 & $.35^{* * *}$ & $.30^{* * *}$ & $-.38^{* * *}$ \\
4. Age & & & & - & $.12^{*}$ & $.17^{* * *}$ & .04 \\
5. Political Orientation & & & & & - & $.69^{* * *}$ & $-.41^{* * * *}$ \\
6. OIS 'Social Change' & & & & & & - & $-.26^{* * * *}$ \\
7. OIS 'Systemic Inequality' & & & & & & & - \\
\hline$M$ & 3.07 & 4.51 & 4.10 & 33.54 & -1.66 & 2.73 & 3.89 \\
$S D$ & 1.01 & 0.79 & .087 & 14.13 & 2.78 & 1.21 & 0.91 \\
\hline
\end{tabular}

Note. 'MFQ-r' and 'OIS' scores range from 1-6 (high scores indicate endorsement of moral domains, and more insecurities, respectively). Political orientation' ranges from -5 (very liberal) to +5 (very conservative). $\quad{ }^{*} p<.05{ }^{* *} p<.01 \quad{ }^{* * * *} p<.001$

As expected, 'Traditionalism' was associated with older age, political conservatism, higher levels of insecurity with social change, and lower levels of concern about systemic inequalities. These relationships provide evidence that the 'Traditionalism' factor appears to be related to a conservative sociopolitical orientation. In contrast, 'Compassion' was unrelated to age, but correlated with political liberalism, lower levels of insecurity about social change, and higher levels of concern about system inequality. As such, 'Compassion' appears to be related to a more left-leaning sociopolitical orientation. The 'Liberty' factor was associated with political conservatism, greater levels of insecurity about social change, and lower levels of concern about systemic inequality. This pattern mirrors that of the 'Traditionalism' factor, albeit with a lesser focus on traditional measures of ideology and a greater focus on the forceful redistribution of social equalities.

Although the MFQ-r factors were correlated with each other in the expected directions, these relationships are generally small in terms of their absolute magnitude.

\section{Predictive Validity of the Revised MFQ (Study 1)}

To examine the predictive validity of the MFQ-r, a binary logistic regression was run to predict self-reported EU referendum voting intentions. Participant demographic information 
(sex, age, and education), self-reported political orientation, OIS factor scores, and the three factors of the MFQ-r were entered as predictors. Further, one-way analyses of variance (ANOVAs) were conducted to establish differences in the endorsement of the MFQ-r moral domains between those voting for identifiable parties in the 2015 UK general election. These analyses were exploratory in nature and designed to provide an indication of the validity of the MFQ-r. As such, we did not make any formal hypotheses, and the results should be considered indicative and in need of independent replication.

Predicting EU referendum voting intentions. The model predicting EU referendum voting intentions was statistically significant, predicting variability in voting intentions, $\chi^{2}(9)$ $=194, p<.001$, Nagelkerke pseudo $R^{2}=.512$. The model accurately classified $79 \%$ of the sample into the 'Remain' and 'Leave' voter categories and was more accurate when predicting an intended 'Remain' vote (87.1\%) than 'Leave' (67.1\%). Multicollinearity was not present with VIF (all < 2.50) and Tolerance values (all > 0.40) being acceptable. Model coefficients are presented in Table 4.

Table 4. Binary logistic regression predicting EU referendum vote intention using the MFQ-r

\begin{tabular}{lcccc}
\hline & $\boldsymbol{B}(\boldsymbol{S E})$ & $\boldsymbol{p}$ & $\boldsymbol{O R}$ & $\mathbf{9 5 \%} \mathbf{C I}(\boldsymbol{O R})$ \\
\hline Sex & $0.24(0.34)$ & .471 & 1.27 & {$[0.66,2.46]$} \\
Age & $0.01(0.01)$ & .636 & 1.01 & {$[0.98,1.03]$} \\
Education & $0.08(0.28)$ & .785 & 1.08 & {$[0.62,1.88]$} \\
Political Orientation & $0.25(0.07)$ & $<.001$ & 1.28 & {$[1.12,1.48]$} \\
OIS 'Social Change' & $0.91(0.17)$ & $<.001$ & 2.48 & {$[1.79,3.44]$} \\
OIS 'Systemic Inequality' & $0.01(0.17)$ & .959 & 1.01 & {$[0.72,1.42]$} \\
MFQ-r 'Traditionalism' & $-0.11(0.21)$ & .594 & 0.89 & {$[0.59,1.36]$} \\
MFQ-r 'Compassion' & $-0.03(0.21)$ & .893 & 0.97 & {$[0.65,1.46]$} \\
MFQ-r 'Liberty' & $0.66(0.17)$ & $<.001$ & 1.94 & {$[1.38,2.71]$} \\
\hline
\end{tabular}

Note. EU vote intention coded as $0=$ Remain, $1=$ Leave. 'Sex' was coded as $0=$ male, $1=$ female. $B$ represents unstandardized log-odds. $O R$ represents the odds of voting 'Leave'. Political orientation ranges from -5 (very liberal) to +5 (very conservative).

Examining the model coefficients, none of the demographic variables of sex, age, or education predicted EU referendum voting intention. Political conservatism, 'social change insecurities', and the 'Liberty' factor of the MFQ-r all predicted an increased likelihood of voting 'Leave'. None of the other variables were significantly associated with referendum voting intentions. 
For comparison, in Harper and Hogue (2019) - where these data originate - using the six-factor MFQ (plus liberty) model yielded a Nagelkerke pseudo $R 2$ value of .468, which is slightly lower than the .512 outcome using the MFQ-r. In this earlier work, MFQ factors on 'Care' and 'Liberty' predicted voting intentions in the directions of 'Remain' and 'Leave', respectively. The same relationships between voting intentions and ideology and 'social change insecurities' were also present in Harper and Hogue (2019).

Party voting differences on the MFQ-r. One-way ANOVAs was run to assess whether MFQ-r factor scores differed as a function of the political party participants voted for in the 2015 UK general election. In this analysis, only those participants with an identifiable Party vote (i.e., an explicitly declared vote for the Conservatives, Labour, Liberal Democrats, UKIP, or the Green Party) were included. This excluded those who voted for 'Other' parties/candidates (owing to the range of potential ideological positions that these parties and candidates could occupy across the political spectrum), and those who 'Did Not Vote'.

There was a significant effect of 'Party vote' on all dependent variables:

'Traditionalism', $F(4,340)=28.10, p<.001$, partial $\eta^{2}=0.25$; 'Compassion', $\chi^{2}(4)=37.50$, $p<.001, \varepsilon^{2}=0.11$; 'Liberty', $F(4,340)=16.80, p<.001$, partial $\eta^{2}=0.17$. Descriptive statistics are presented in Table 5.

Table 5. Descriptive statistics for MFQ-r factor scores, by 2015 general election vote

\begin{tabular}{lccccccc}
\hline & & \multicolumn{2}{c}{ Traditionalism } & & \multicolumn{2}{c}{ Compassion } & \multicolumn{2}{c}{ Liberty } \\
\cline { 2 - 7 } & $\boldsymbol{n}$ & $\boldsymbol{M}$ & $\boldsymbol{S D}$ & $\boldsymbol{M}$ & $\boldsymbol{S D}$ & $\boldsymbol{M}$ & $\boldsymbol{S D}$ \\
\hline Conservatives & 65 & 3.96 & 0.82 & 4.33 & 0.79 & 4.26 & 0.77 \\
Labour & 137 & 3.09 & 0.77 & 4.75 & 0.68 & 3.79 & 0.83 \\
Liberal Democrats & 47 & 3.05 & 0.76 & 4.57 & 0.52 & 4.13 & 0.78 \\
UKIP & 47 & 3.84 & 0.91 & 3.95 & 0.93 & 4.88 & 0.93 \\
Green Party & 49 & 2.64 & 0.80 & 4.62 & 0.87 & 3.92 & 0.80 \\
\hline
\end{tabular}

Note. MFQ-r factor scores range from 1-6, with high scores indicating greater levels of endorsement of the respective moral domain.

Post-hoc comparisons were calculated with $p$ values amended using the Bonferroni correction. These comparisons are also presented in Figure 2.

In relation to 'Traditionalism', those who voted Conservative scored significantly higher than all other party voters (all $p \mathrm{~s}<.001, d \mathrm{~s}>1.09$ ) with the exception of UKIP voters $(p=.100, d=0.15)$. Labour voters scored lower than those who voted for the Conservatives $(p<.001, d=0.1 .09)$ and UKIP $(p<.001, d=0.94)$, but higher than those who voted for the 
Green Party $(p=.010, d=0.55)$. Liberal Democrat voters differed only from Conservative ( $p$ $<.001, d=1.14)$ and UKIP ( $p<.001, d=0.99)$ voters, scoring lower than both of these groups. Those who voted for the Green Party scored lower on this MFQ-r factor than all other groups (all $p \mathrm{~s}<.010 ; d \mathrm{~s}=0.55-1.64$ ), with the exception of those voting for the Liberal Democrats $(p=.143, d=0.50)$.

In the 'Compassion' domain, scores violated assumptions for normality and so the nonparametric Kruskal-Wallis test was used, with post-hoc Dwass-Steel-Critchlow-Fligner (DSCF) comparisons used. Conservative voters scored lower than those voting for Labour ( $W$ $=5.29, p=.002$, but did not differ significantly from the voters of any other parties $(p \mathrm{~s} \geq$ .133. Elsewhere, UKIP voters scored significantly lower in 'Compassion' when compared to Labour voters $(W=7.59, p<.001)$, Liberal Democrats $(W=5.02, p=.004)$, and Green Party voters $(W=5.37, p=.001)$.

On the 'Liberty' factor, UKIP voters scored higher than those who voted for the Conservatives $(p=.001, d=0.75)$, Labour $(p<.001, d=1.33)$, the Liberal Democrats $(p<$ $.001, d=0.91)$, and the Green Party ( $p<.001, d=1.17$ ). Further, Conservative voters scored higher than Labour voters $(p=.001, d=0.58$ ). No other comparisons were statistically significant. 


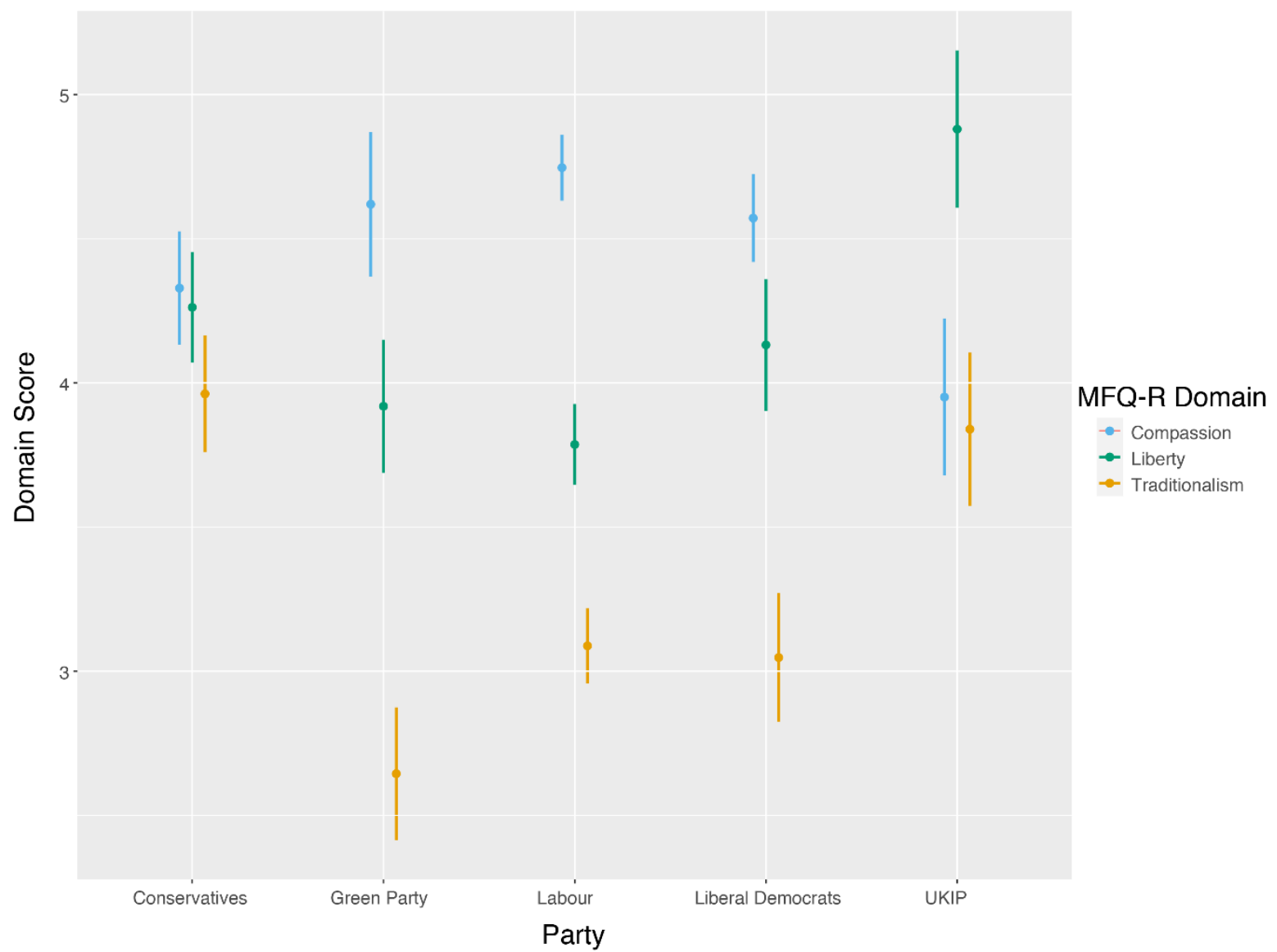

Figure 2. Means plot for MFQ-r factor scores, by 2015 UK general election party vote. Error bars represent $95 \%$ CIs

To summarize Study 1, we found that combining Iyer et al.'s (2012) liberty-related items with the existing MFQ led to a three-factor structure comprised on 'Traditionalism', 'Compassion', and 'Liberty' domains. These were associated with self-reported political orientation and voting behavior in a manner that made theoretical sense (i.e., 'Traditionalism' was associated with conservatism and rightward voting, 'Compassion' with liberalism and leftward voting, and 'Liberty' had a weak association with orientation but predicted a strong preference for a Brexit vote).

\section{Study 2}

In Study 2 we sought to confirm the factor structure reported in Study 1, and to further offer evidence of this through a network analysis of MFQ-r. We also offer a further exploratory analysis of the associations between MFQ-r domains and voting behavior in a more recent sample to replicate our previous results. 


\section{Methods}

\section{Participants}

Participants for this study were recruited as part of a larger project pertaining to ideological responses to the COVID-19 pandemic. This sample contains all those who completed the MFQ in that project. Thus, a total of 322 participants $\left(61 \%\right.$ female; $M_{\text {age }}=$ 39.79 years, $S D=14.80$ ) were included in this study. Participants were recruited in line with those methods reported for Study 1, making use of Reddit political forum discussions, and local interest community groups on Facebook. These methods allowed us to sample a crosssection of the community that may be unavailable using traditional student samples or via paid services such as Amazon's Mechanical Turk.

\section{Measures}

Demographics. Participants were asked to provide basic demographic information (sex, age, self-reported political ideology, and past voting behavior). Specifically, we asked about their voting in the 2019 UK General Election and the 2016 EU referendum. We also asked about a hypothetical re-run of the referendum to capture participants' most recent views on this topic. Inclusion criteria for participation dictated that all who completed the online survey were over the age of 18 years, and resident in the UK.

Moral Foundations Questionnaire. We again used the full 32-item MFQ (Graham et al., 2009) alongside Iyer et al.'s (2012) liberty items in this study and used scoring syntax provided on MoralFoundations.org. Average domain scores and internal consistency coefficients are provided in Table 6 (see Results, below).

Unreported measures and tasks. As part of the broader project, we also asked participants to complete a measure pertaining to their levels of fear of COVID-19, and to respond to some scenarios about the flouting of governmental public health advice. The results of this study are reported at Harper and Rhodes (2020).

\section{Procedure}

After clicking survey link, participants read information about the nature of the study before affirming their consent. Participants provided demographic information, before the MFQ and the fear of COVID-19 scale in a randomized order, followed by providing their judgements of COVID-19 behavioral transgressions. As such, the completion of the MFQ 
was unaffected by potential exposure to COVID-related ideologically salient stimuli. Once finished, all participants were comprehensively debriefed. This procedure was approved by an institutional review committee and adhered to British Psychological Society ethical guidelines.

\section{Results}

An anonymized version of the dataset (in .omv format) is available for download at https://osf.io/nwpb6/?view_only=dc6886f6192b47cabf09dc99b04d5cce.

\section{Confirmatory Factor Analysis}

A confirmatory factor analysis was run on the MFQ data using the lavaan R package in jamovi (Rosseel et al., 2020). We used the three-factor MFQ-r structure reported in Study 1 as the default model. We also ran a confirmatory analysis on the original MFQ structure to replicate the findings of other teams (e.g., Iurino \& Saucier, 2020; Kim et al., 2012; Kivikangas et al., 2017; Nilsson \& Erlandsson, 2015; Yilmaz et al., 2016).

The default model led to unacceptable model fit statistics, $C F I=.77, T L I=.74$, RMSEA $=.08$ [90\% CI: .08, .09]. As such, we examined modification indices, but none of these led to changes that could be made within factors. We then examined residuals of the observed correlation matrix, using \pm 0.1 as a criterion for a potential issue. There were several of these issues, with two 'Liberty' items and one 'Compassion' item deviation from their predicted correlations across many other items. These items were removed from the scale and the analysis re-run. Observing the residual correlation matrix once again, we saw that one 'Traditionalism' item deviated from its predicted correlations with almost all other items. A further 'Liberty' item also had a low standardized factor loading (0.21). We therefore removed these items to improve model fit. A list of all item loadings can be found in Table 6 .

This led to improved model fit statistics, $\chi^{2}(132)=335, p<.001, C F I=.87, T L I=.85$, RMSEA $=.07$ [90\% CI: .06, .08]. These coefficients suggested that the MFQ-r three-factor model does not lead to a substantially worse fit (and in some cases in superior) when compared to:

- the original five-factor MFQ, $C F I=.73, T L I=.70, R M S E A=.08$

- the traditional six-factor MFQ, $C F I=.66, T L I=.64, R M S E A=.08$ 
- a second-order two-factor model ('individualizing' - comprising the care and fairness items - and 'binding' - comprising the loyalty, authority, and purity items) for the original MFQ, $C F I=.72, T L I=.64, R M S E A=.08$

- a second-order three-factor model ('individualizing' and 'binding', plus the Iyer et al. 'liberty' items) for the original MFQ, $C F I=.66, T L I=.62, R M S E A=.08$.

All models that were run can be downloaded from https://osf.io/nwpb6/?view_only=dc6886f6192b47cabf09dc99b04d5cce. This address also contains the final version of the MFQ-r.

The Traditionalism ( $\alpha=.85$, McDonald's $\omega=.85)$ and Compassion $(\alpha=.76$, McDonald's $\omega=$.76) MFQ-r factors demonstrated acceptable levels of reliability. Liberty, however, fell short of the level of acceptability $(\alpha=.54$, McDonald's $\omega=.59)$. This likely stems from an issue with the collection of liberty items put forward by Iyer et al. (2012), which in its original form also had low levels of internal consistency $(\alpha=.63)$. On the original MFQ, internal consistency was acceptable for the binding foundations of loyalty, authority, and purity ( $\alpha \mathrm{s}=.74, .79, .71)$, but not for the individualizing foundations of care/harm and fairness $(\alpha \mathrm{s}=.66, .61)$. As such, while acknowledging the limitations of the MFQ-r, we argue that its better fit and otherwise strong internal consistency offers a superior measurement structure of moral intuitions than does the original MFQ format. Moral domain scores for each model, and their inter-correlations, are presented in Table 7. 
Table 6. Item loadings in final confirmatory factor analysis

\begin{tabular}{|c|c|c|c|c|c|c|}
\hline \multirow[b]{2}{*}{ Factor } & \multirow[b]{2}{*}{ Indicator } & \multirow[b]{2}{*}{ Est. (SE) } & \multicolumn{2}{|c|}{ 95\% CI (Est.) } & \multirow[b]{2}{*}{$p$} & \multirow{2}{*}{$\begin{array}{c}\text { Stand. } \\
\text { Estimate }\end{array}$} \\
\hline & & & Lower & Upper & & \\
\hline \multirow[t]{9}{*}{ Traditionalism } & RESPECT & $1.16(0.07)$ & 1.02 & 1.29 & $<.001$ & 0.82 \\
\hline & KIDRESPECT & $0.88(0.07)$ & 0.75 & 1.02 & $<.001$ & 0.67 \\
\hline & HARMLESSDG & $0.76(0.09)$ & 0.58 & 0.94 & $<.001$ & 0.47 \\
\hline & DECENCY & $0.99(0.08)$ & 0.83 & 1.13 & $<.001$ & 0.67 \\
\hline & DISGUSTING & $0.86(0.07)$ & 0.72 & 1.00 & $<.001$ & 0.63 \\
\hline & TRADITIONS & $0.90(0.07)$ & 0.76 & 1.04 & $<.001$ & 0.66 \\
\hline & UNNATURAL & $0.66(0.09)$ & 0.49 & 0.83 & $<.001$ & 0.44 \\
\hline & LIBERTY_1 & $0.76(0.07)$ & 0.62 & 0.89 & $<.001$ & 0.59 \\
\hline & LOVECOUNTRY & $0.98(0.08)$ & 0.83 & 1.14 & $<.001$ & 0.66 \\
\hline \multirow[t]{5}{*}{ Compassion } & UNFAIRLY & $0.69(0.06)$ & 0.58 & 0.80 & $<.001$ & 0.69 \\
\hline & CRUEL & $0.79(0.06)$ & 0.68 & 0.90 & $<.001$ & 0.76 \\
\hline & RIGHTS & $0.59(0.06)$ & 0.47 & 0.71 & $<.001$ & 0.56 \\
\hline & WEAK & $0.51(0.06)$ & 0.39 & 0.63 & $<.001$ & 0.50 \\
\hline & EMOTIONALLY & $0.64(0.06)$ & 0.52 & 0.76 & $<.001$ & 0.59 \\
\hline \multirow[t]{4}{*}{ Liberty } & LIBERTY_4 & $0.78(0.09)$ & 0.60 & 0.96 & $<.001$ & 0.61 \\
\hline & LIBERTY_6 & $0.88(0.09)$ & 0.70 & 1.06 & $<.001$ & 0.73 \\
\hline & LIBERTY_9 & $0.39(0.11)$ & 0.18 & 0.61 & $<.001$ & 0.25 \\
\hline & LIBERTY_7r & $0.57(0.09)$ & 0.40 & 0.74 & $<.001$ & 0.45 \\
\hline
\end{tabular}

Note. 'Est.' relates to unstandardized item loading. 'Stand. Estimate' represents the standardized coefficient. Item loadings in earlier iterations of the confirmatory factor analysis are downloadable from the project Open Science Framework page. 
Table 7. Inter-correlations between MFQ domains

\begin{tabular}{|c|c|c|c|c|c|c|c|c|c|}
\hline \multirow[b]{2}{*}{ Variable } & \multicolumn{6}{|c|}{ Standard MFQ (plus Iyer et al.'s (2012 'Liberty' scale) } & \multicolumn{3}{|c|}{$\underline{\text { MFQ-r }}$} \\
\hline & 1 & 2 & 3 & 4 & 5 & 6 & 7 & 8 & 9 \\
\hline 1. MFQ Harm & - & & & & & & & & \\
\hline 2. MFQ Fairness & $.59^{* * *}$ & - & & & & & & & \\
\hline 3. MFQ Loyalty & $.18^{* * *}$ & .05 & - & & & & & & \\
\hline 4. MFQ Authority & $.19^{* * *}$ & .06 & $.73^{* * *}$ & - & & & & & \\
\hline 5. MFQ Purity & $.27^{* * *}$ & $.17^{* *}$ & $.63^{* * *}$ & $.68^{* * *}$ & - & & & & \\
\hline 6. MFQ Liberty & $.22^{* * *}$ & $.20^{* * *}$ & $.39^{* * *}$ & $.38^{* * *}$ & $.30^{* * *}$ & - & & & \\
\hline 7. MFQ-r Traditionalism & $.31^{* * *}$ & $.18^{* *}$ & $.77^{* * * *}$ & $.86^{* * *}$ & $.85^{* * *}$ & $.40^{* * *}$ & - & & \\
\hline 8. MFQ-r Compassion & $.75^{* * *}$ & $.73^{* * *}$ & $.16^{* *}$ & $.17^{* *}$ & $.22^{* *}$ & $.28^{* * *}$ & $.30^{* * *}$ & - & \\
\hline 9. MFQ-r Liberty & .05 & .02 & $.25^{* * *}$ & $.20^{* * * *}$ & $.22^{* * *}$ & $.83^{* * *}$ & $.23^{* * *}$ & .07 & - \\
\hline$M$ & 4.78 & 4.64 & 3.24 & 3.72 & 3.09 & 3.81 & 3.66 & 4.80 & 3.31 \\
\hline$(S D)$ & 0.74 & 0.67 & 0.92 & 0.98 & 0.91 & 0.65 & 0.95 & 0.74 & 0.87 \\
\hline$\alpha / \omega$ & $.66 / .69$ & $.61 / .66$ & $.74 / .75$ & $.79 / .80$ & $.71 / .71$ & $.63 / .63$ & $.85 / .85$ & $.76 / .76$ & $.54 / .59$ \\
\hline Model fit & & CFI & $\begin{array}{l}2(687)=2 \\
.66 ; \text { TLI }=\end{array}$ & $\begin{array}{l}3, p<.0 \\
4 ; \mathrm{RMSE}\end{array}$ & $=.08$ & & $\begin{array}{r}\chi^{2} \\
\mathrm{CFI}=.8\end{array}$ & $\begin{array}{l}=335, p \\
\mathrm{I}=.85 ; \mathrm{F}\end{array}$ & $\begin{array}{l}001 ; \\
\mathrm{SEA}=.07\end{array}$ \\
\hline
\end{tabular}

Note. Data relate to the final structure, after item removals during confirmatory factor analysis

${ }^{*} p<.05^{* *} p<.01 \quad{ }^{* * *} p<.001$ 


\section{Parallel Network Analysis of the Revised MFQ}

A network is an abstract representation of a system of related variables. Such analyses have recently gained popularity in survey design as an alternative to confirmatory and exploratory factor analyses (e.g., Borsboom, 2008; Cramer et al., 2010; Boschloo et al., 2016; McNally et al., 2015; van Borkulo et al., 2015; van de Leemput et al., 2014; van der Maas et al., 2006).

A network has two primary components: nodes and edges. Nodes represent the variables of interest in a study (i.e., scale items) and edges connect the nodes into a superstructure via their pairwise interactions. Once a network is formed, network analysis gives us the power to observe complex relationships between variables, but also to study the most important or least important nodes within a system (Borsboom et al., 2011; see also Costantini et al., 2019; Dalege et al., 2017; Epskamp et al., 2018). We leveraged network analysis to provide a complimentary investigation of the MFQ-r and its structure, owing to the borderline acceptable levels of some model fit statistics. It is important to note that we performed the following network analysis completely blind. That is, we did not tell the network anything about the expected structure of the MFQ-r (i.e., the network was untrained).

We submitted all the MFQ items to a network analysis in JASP (JASP Team, 2020). EBICglasso network analysis (Epskamp et al., 2012; 2017) was used to generate the network illustrated in Figure 3. This approach takes the individual elements of a network and imposes lasso regularization which estimates a concentration matrix. The glasso method maximizes a penalized log-likelihood (instead of a log-likelihood function), with the penalty equal to the tuning parameter $\lambda$ multiplied by the absolute sum of the elements within a concentration matrix (Friedman et al., 2008). We used the Extended Bayesian Information Criterion (EBIC; Chen \& Chen, 2008; Epskamp, 2016; Foygel \& Drton, 2010) to estimate the network, which takes into account model complexity and model fit (to penalize over-fitted models). This results in networks that are more accurate and easier to interpret than other methods (Tibshirani, 1996). We used the 'spring' method of the Frutherman-Reingold visualization algorithm (Fruchterman \& Reingold, 1991), which is based on the strengths of the edges between nodes, to produce the network.

By visually inspecting the network we can immediately see the presence of three separate communities. Allied to this, the centrality plot in Figure 4 highlights the degree, expected influence, betweenness, and closeness of the nodes within the network. The degree and expected influence parameters for each node tell us about the importance of that node 
within the network. As shown in Figure 4, the RESPECT item ("Whether or not someone showed a lack of respect for authority") has the highest expected influence and degree scores, and as such has strong and direct connections with many other nodes. Nodes can also be central in terms of their betweenness, which indexes how often a node is the shortest distance between two other nodes. The closeness parameter indexes how many indirect and direct paths are 'shorter' between nodes. The strongest and most influential MFQ nodes are highlighted in Figure 4. Critically, the most interesting observation from this analysis is that the clusters of nodes identified from the network almost perfectly correspond to the results of our exploratory and confirmatory factor analyses, giving converging evidence from different statistical techniques that the MFQ should be conceptualized in line with the MFQ-r.

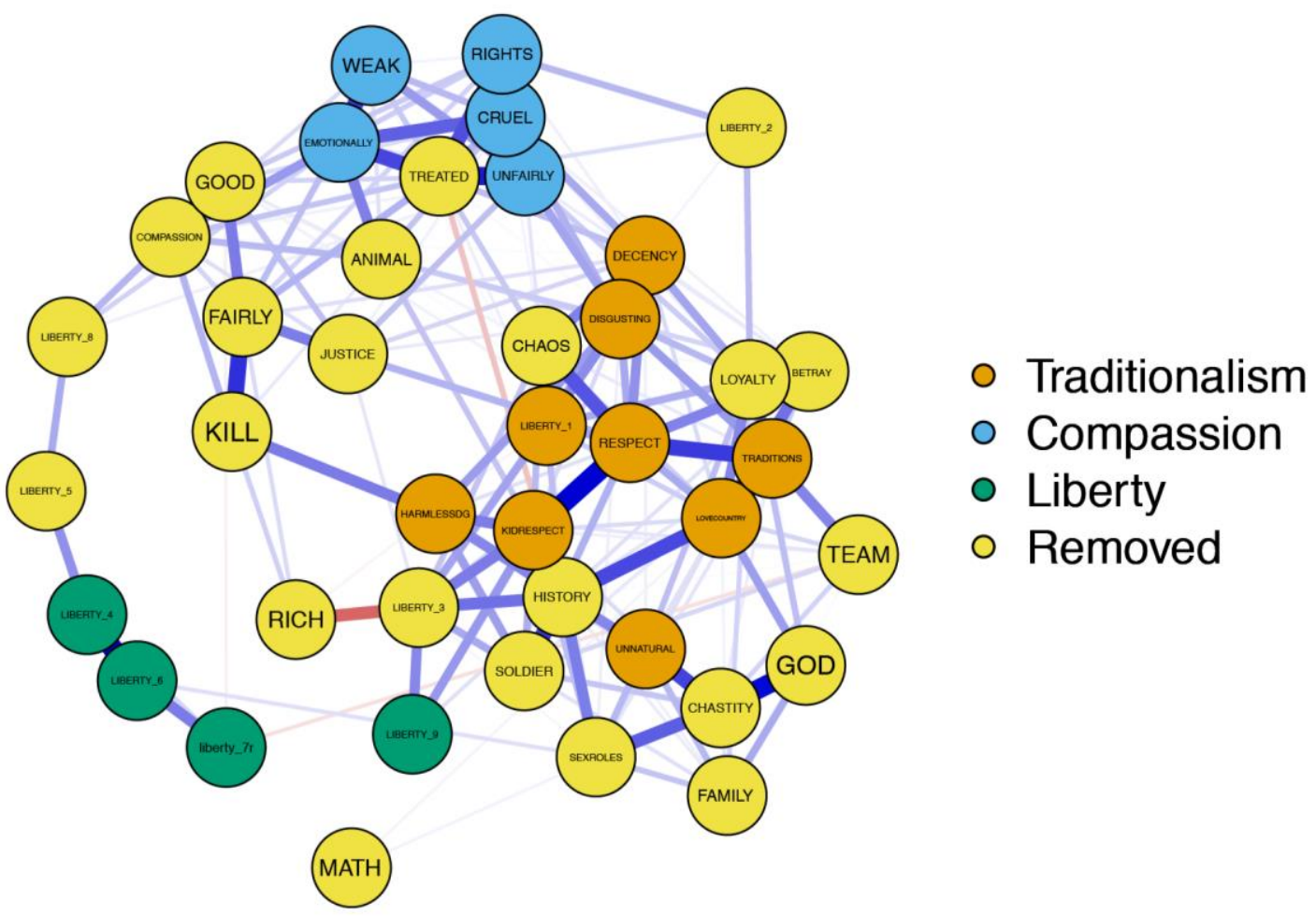

Figure 3. A network of the MFQ. Red lines indicate negative associations between symptoms; blue lines indicate positive associations between symptoms; thicker lines indicate stronger associations. To facilitate interpretation, we have colored the nodes that correspond to the MFQ-r domains of Traditionalism, Compassion, and Liberty. Yellow nodes represent items that were removed from the MFQ after the exploratory factor analysis (Study 1) and CFA (Study 2). 

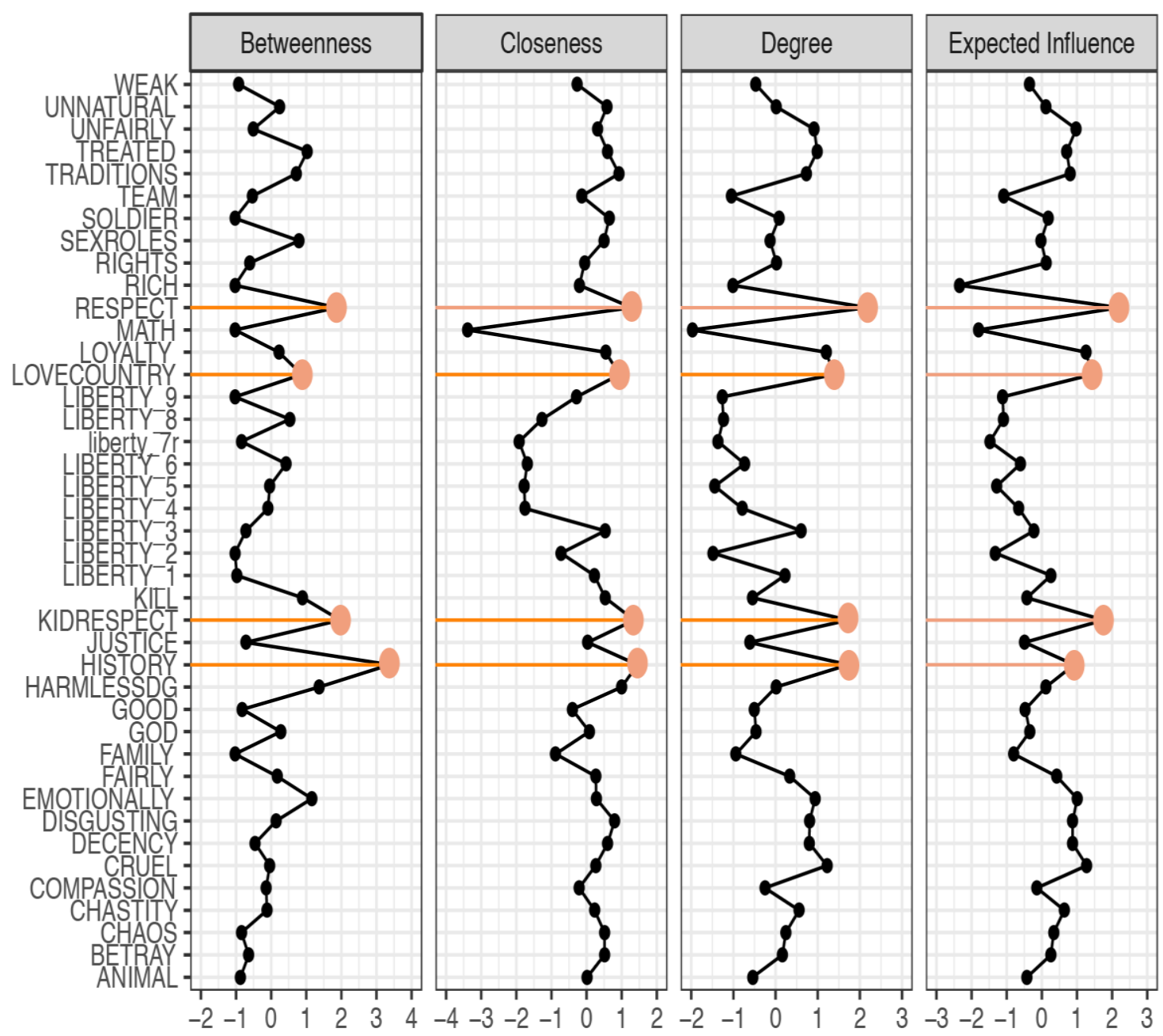

Figure 4. A Centrality plot of the MFQ. The plot is standardized $(M=0, S D=1)$, where larger scores indicate greater centrality for each measure. Most central items are marked with an orange dot for clarity.

\section{Concurrent Validity of the Revised MFQ (Study 2)}

We sought to replicate the findings of Study 1 by examining the relationships between the MFQ-r domains and self-reported political ideology, voting in the 2019 UK General Election, and preferences over the Brexit issue. Although we asked participants both their actual EU referendum vote and their hypothetical preference in a hypothetical re-run of the vote, we only analyzed data for the latter of these as it was the more temporally valid outcome in our cross-sectional design. Owing to the function of this analysis, we did not make any formal hypotheses at the outset.

Consistent with Study 1, self-reported conservatism was positively related to endorsing MFQ-r Traditionalism $(r=.51, p<.001)$, and negatively related to endorsing MFQ-r Compassion $(r=-.12, p=.030)$. However, the magnitude of the associated with scores on the 
Compassion domain was around half of that reported in Study 1. The small relationship between conservatism and MFQ-r Liberty was consistent with Study $1(r=.18, p=.002)$.

'Traditionalism' scores were not normally distributed, and there were unequal variances between groups; this violated the assumptions for ANOVA, and so non-parametric tests were used. We found significant effects of 'Party vote' in relation to MFQ-r Traditionalism $\left(\chi^{2}(3)\right.$ $\left.=93.90, p<.001, \varepsilon^{2}=0.30\right)$ and MFQ-r Liberty $(F(3,315)=5.41, p=.001)$, but not MFQ-r Compassion $(F(3,315)=0.51, p=.675)$. Examining the mean scores on each variable (Table 8), Conservative Party voters and those who did not vote scored higher on the MFQ-r Traditionalism domain (comparative to Labour Party and 'other' voters; all $p$ s $<.001, d=$ 0.48). The effect of Party vote for MFQ-r Liberty was driven by higher scores among Conservatives than those who voted for either Labour $(p=.004)$ or another unnamed Party ( $p$ $=.014, d=0.50)$.

Table 8. Descriptive statistics for MFQ-r factor scores, by 2019 general election vote

\begin{tabular}{lccc}
\hline & & MFQ-r domain & \\
& Traditionalism & Compassion & Liberty \\
\hline The Conservative Party $(n=82)$ & $4.43(0.67)$ & $4.85(0.78)$ & $3.59(0.95)$ \\
The Labour Party $(n=147)$ & $3.34(0.88)$ & $4.77(0.76)$ & $3.18(0.76)$ \\
Another Party $(n=67)$ & $3.25(0.87)$ & $4.77(0.0)$ & $3.16(0.86)$ \\
Did not vote $(n=24)$ & $3.13(0.70)$ & $4.93(0.57)$ & $3.56(0.98)$ \\
\hline
\end{tabular}

Note. Values represent mean values with $\pm 1 S D$ in parentheses.

We ran a binary logistic regression predicting current preferences in the Brexit debate. Sex, age, self-reported political ideology, and the three MFQ-r domains were entered as predictors. There was no evidence of multicollinearity in the model, with VIF (all < 1.47) and Tolerance coefficients (all > 0.68) being acceptable. This model was statistically significant, $\chi^{2}(6)=161, p<.001$, Nagelkerke pseudo $R^{2}=.583$. The model accurately classified $85.7 \%$ of the sample into their respective preferences and, consistent with Study 1, was more accurate when predicting a preference for 'Remain' (89.4\%) than for 'Leave' (77.4\%). Model coefficients are presented in Table 9. 
Table 9. Binary logistic regression predicting Brexit views using the MFQ-r

\begin{tabular}{lcccc}
\hline & $\boldsymbol{B}(\boldsymbol{S E})$ & $\boldsymbol{p}$ & $\boldsymbol{O R}$ & $\mathbf{9 5 \%}$ CI $(\boldsymbol{O R})$ \\
\hline Sex & $0.33(0.38)$ & .394 & 1.388 & {$[0.65,2.95]$} \\
Age & $0.02(0.01)$ & .023 & 1.028 & {$[1.00,1.05]$} \\
Political Orientation & $0.78(0.13)$ & $<.001$ & 2.179 & {$[1.69,2.81]$} \\
MFQ-r 'Traditionalism' & $0.94(0.30)$ & .002 & 2.559 & {$[1.43,4.58]$} \\
MFQ-r 'Compassion' & $-0.21(0.31)$ & .490 & 0.810 & {$[0.45,1.47]$} \\
MFQ-r 'Liberty' & $0.88(0.23$ & $<.001$ & 2.400 & {$[1.54,3.74]$} \\
\hline
\end{tabular}

Note. EU vote intention coded as $0=$ Remain, $1=$ Leave. 'Sex' was coded as $0=$ male, $1=$ female. $B$ represents unstandardized log-odds. $O R$ represents the odds of voting 'Leave'. Political orientation ranges from 1 (very liberal) to 10 (very conservative).

Examining the coefficients, voting 'Leave' was predicted by older age, higher conservatism, and a greater endorsement of the MFQ-r domains of Traditionalism and Liberty. MFQ-r Compassion was unrelated to Brexit attitudes.

For comparison, the six-factor MFQ also led to a significant regression model, $\chi^{2}(9)=$ $169, p<.001$, Nagelkerke pseudo $R^{2}=.599$. This model correctly classified a similar proportion of the sample to that described for the MFQ-r (total $=85.9 \%$; 'Remain' $=90.5 \%$; 'Leave' $=75.8 \%$ ). Within the model the effect of political orientation remained consistent. For the MFQ, endorsement of the fairness foundation $(O R=0.39, p=.009)$ predicted lower odds of voting 'Leave', while this choice was more likely among those who endorsed the loyalty $(O R=1.90, p=.040)$, purity $(O R=2.02, p=.029)$, and liberty foundations $(O R=$ $3.29, p<.001)$. These data are broadly consistent with previous datasets (e.g., Harper \& Hogue, 2019).

\section{Study 2 Summary}

To summarize Study 2, we were able to confirm the three-factor MFQ-r structure that was reported in Study 1 using both confirmatory factor analysis and network analyses. We were also able to replicate (with some changes in the magnitude of correlations) the associations between the MFQ-r and both political orientation and voting behavior.

\section{General Discussion}

\section{Overview of Key Findings}

This paper has presented a reanalysis of the MFQ in response to criticisms about the measure's unreliable factor structure (Davis et al., 2017; Iurino \& Saucier, 2020; Kim et al., 2012; Kivikangas et al., 2017; Nilsson \& Erlandsson, 2015; Yilmaz et al., 2016) and poor 
internal consistency at the foundation level (Graham et al., 2009; 2011; 2012; Harper \& Hogue 2019).

Parallel analysis indicated that five factors underpinned the MFQ (when also including the liberty items produced by Iyer et al., 2012). However, only three of these met our criteria for psychometric (minimum five items) in the initial exploratory factor analysis) and theoretical meaningfulness. These factors were labelled 'Traditionalism', 'Compassion', and 'Liberty'. Each of these factors contained clear and unique themes, were unrelated to each other, and were internally consistent. Further, concurrent validity of the 'Traditionalism' and 'Compassion' factors was supported via significant correlations with 'social change' insecurities (positive and negative relationships, respectively) and anxieties about 'systemic inequality' (negative and positive relationships, respectively). In turn, 'Traditionalism' was correlated with political conservatism, 'Compassion' with political liberalism, and 'Liberty' was slightly associated with a rightward-leaning political orientation. Significant differences in the endorsement of these three moral domains were found when comparing the voter groups. That is, 'Traditionalism' was more strongly endorsed by those who voted for rightleaning parties (e.g., the Conservatives and UKIP), while 'Compassion' was more strongly endorsed by those who voted for the political left (e.g., Labour, Liberal Democrats, and the Green Party). 'Liberty' was generally endorsed at an equal level across the voting spectrum, with the exception being among UKIP voters who were the group to most strongly endorse 'Liberty'-based moral principles. While these party-specific differences were only observed in Study 1 (indicating that moral intuitions may be particularly influential during election periods), they were broadly consistent across both studies when considering the more pervasive issue of Britain's membership of the EU. In this case, traditionalism (or aspects of this construct, such as insecurities about systemic change) and liberty were associated with a greater propensity to favor the vote to leave the EU, consistent with previous research using the five-factor MFQ model (Harper \& Hogue, 2019).

The confirmatory factor analysis presented in Study 2 was less clear-cut than Study 1 may have predicted. Several items loaded poorly onto their initial components, leading to their removal from the final MFQ-r. The resultant scale demonstrated broadly acceptable model fit indices in relation to SRMR and RMSEA consistent with past work on the MFQ (albeit with superior internal consistency coefficients in this revised structure). Further, the three-factor structure fit the data better than the initial five-factor structure, or the extended six-factor structure brought about by combining the initial MFQ with Iyer et al.'s (2012) liberty items. 


\section{Implications of these Data}

The analyses presented in this paper have implications for the ways in which the MFT is conceptualized and measured. From a conceptual perspective, the lack of confirmatory support for a five-factor MFQ structure in previous studies (Iurino \& Saucier, 2020; Kim et al., 2012; Kivikangas et al., 2017; Yilmaz et al., 2016), or a six-factor structure in the exploratory work undertaken in the current paper, raises doubt about this model. In short, these data do not support MFT's five factor structure.

In support of this view, some researchers have dispensed with the five- or six-factor structure, and instead use the broad categories of 'individualizing' (a combination of care and fairness) and 'binding' (a combination of authority, loyalty, and purity) foundations (see Alper \& Yilmaz, 2020; Barnett et al., 2018; Malka et al., 2016; Napier \& Luguri, 2013; Smith et al., 2014). These cited works do not consider Iyer et al.'s (2012) liberty-related items, as they did not form a core part of the initial MFQ (Graham et al., 2009, 2012). There are conceptual links between 'Traditionalism' and binding foundations, and between 'Compassion' and individualization. Adopting the three-factor structure of the MFQ-r would be consistent with this prior work, while also incorporating the liberty foundation into a core measure of the MFT. While an objection to parsimony in favor of a more pluralistic view of morality is a cornerstone of the MFT (Graham et al., 2013), the available data seem to suggest that a more parsimonious model is better reflective of the empirical structure of morality, at least in relation to the contents of the MFQ as it is currently formulated. That said, even the MFQ-r presented here should be considered a preliminary or temporary solution to a problem that has dogged the MFQ literature for some time. The initial development paper for the MFQ (Graham et al., 2009) provided little detail about the formal psychometric development process, including how items were selected for inclusion on the questionnaire. Given the popularity and widespread use of the moral foundations framework, a substantive field-wide project may be necessary to pool resources and systematically test a larger pool of potential MFQ items. Thus, we are not advocating the MFQ-r as the final form of the MFQ. Instead, it offers a better version than the current form and may be a psychometrically stronger option than the former iteration. However, more widespread and systematic work is required to produce a measure that best reflects the true structure of moral intuitions (see below).

In terms of the broader implications of moving forward (at least temporarily) with the three-factor structure, it appears as though the endorsement of 'Traditionalism' and 'Compassion' moral domains are more linked to higher level political identity (in the current 
sample, this relates to self-placement on the left-right political spectrum, and party vote choice) than is the 'Liberty' domain. This is exemplified in the significant (and opposite) correlations between 'Traditionalism' and 'Compassion' with political orientation, and the significant differences between voters of the various political parties in relation to average scores on these factors. As such, 'Traditionalism' may represent a core moral concern for those who are temperamentally-inclined to express a broad suite of conservative-typical viewpoints (Duckitt et al., 2010; Johnson \& Tamney, 2001), while 'Compassion' appears to represent the core moral value of those with a liberal political identity (see also Hirsch, 2010).

For 'Liberty', the relationship to political beliefs and behavior appears more nuanced. While a small significant correlation was observed with political orientation (in the direction of political conservatism), the magnitude of this relationship leaves the meaningfulness of this link open to doubt. Instead, it may be that, as opposed to broad ideological positions and fixed partisan identity, a predominant endorsement of the 'Liberty' moral domain (comparative to 'Traditionalism' and 'Compassion') informs policy-specific decisionmaking. That is, in the current sample it was those participants who voted for UKIP (the party most vocally supporting a 'Leave' vote in the 2016 referendum on EU membership) in 2015 who endorsed the 'Liberty' domain to the greatest extent. In line with this, the newly conceptualized 'Liberty' domain was a strong predictor of an intended 'Leave' vote in the current sample, as was the full (Iyer et al., 2012) liberty foundation measure in Harper and Hogue's (2019) work on the psychological underpinnings of the Brexit vote.

\section{Limitations and Future Directions}

The work presented in this paper should be viewed as exploratory in nature, and as such does require confirmation in large, independent, and cross-cultural samples. The use of exclusively British samples is a major limitation of this work. At present, no large international datasets exist wherein the full 30-item MFQ and the liberty items from Iyer et al. (2012) have been administered. This prevented us from testing measurement invariance across samples and countries. In previous work, the structure MFQ has not been invariant, meaning that the five-factor model hypothesized in MFT may not be applicable across cultures (Iurino \& Saucier, 2020). Although this past work used the 20-item short form of the MFQ, there is little reason to believe this does not translate to the full form, or indeed the liberty items. However, recent work by Brandt et al. (2020) suggest that a lack of 
measurement invariance in ideological measures do not affect conclusions about political differences.

Nonetheless, as stated earlier the data do suggest that further work on the MFQ may be warranted in order to improve the confidence that social scientists can have its validity and utility. The three-factor structure itself may be questioned, owing to the limited item pool used to develop it. That is, the 41 items used in the PCA were sourced from the original MFQ (Graham et al., 2011) and the liberty items produced by Iyer et al. (2012). As such, it may be that these items themselves introduced bias to the measures, and that a larger pool of potentially morality-relevant items could yield a different factor structure (see also Curry et al., 2019). Given the efficiency of online crowdsourcing for social scientific research (Hauser \& Schwarz, 2016), it may be possible to generate a large pool of potential items, from across the ideological spectrum, for each of the moral foundations. Data in relation to this large item pool could then be subject to factor analytic procedures in order to test competing models, such as the two-factor 'individualizing-binding' foundations model, the three-factor model reported here, and the five- and six-factor models advanced in the orthodox MFT literature. It may be that a hierarchical model, perhaps with the three MFQ-r domains as superordinate factors, might be the optimal solution. If so, future work might try to develop scales that increase the discrimination of these proposed moral foundations, or even to try to generate a new lower-order structure. Conducting this work was beyond the scope of this individual paper and will require broad collaboration across research groups internationally to study the true nature of human moral intuitions. We would encourage scholars to make use of collaborative open science platforms (e.g., StudySwap; https://osf.io/meetings/studyswap/) to bring this much needed endeavor to fruition. Such collaborative work might equally confirm the predictive validity of the MFQ-r in a range of socio-political domains (e.g., voting behavior, specific policy attitudes, prosocial and interpersonal behaviors).

From a practical perspective, more work on the predictive validity of the three factors of the MFQ-r could lead to more developed insights pertaining to political decision-making. This is particularly the case in relation to the 'Liberty' domain, which may be less tied to fixed political allegiances and more amenable to issue-specific changes in voting habits. For example, in the current sample this domain was highest among 2015 UKIP voters, potentially due to this party advocating for a 'Leave' vote in the 2016 referendum and liberty being a key predictor of a preference for this outcome (see Harper \& Hogue, 2019). However, the UKIP vote collapsed in subsequent general elections, with the Conservative Party gaining many of these votes following a realignment to see-through the Brexit process (Cutts et al., 2020). 
Future longitudinal studies, tracking voting preferences over time in response to specific political issues, could illuminate how the 'Liberty' domain affects judgments of specific political issues.

\section{Conclusions}

This paper has presented a reanalysis of Graham et al.'s (2009) MFQ, taking into account the later addition of items related to the liberty foundation (Iyer et al., 2012) and recent questions being raised about the MFQ's factor structure and internal consistency. The three factors underpinning the MFQ-r may reflect a more parsimonious model of morality that (a) is consistent with previous theorizing about the nature of morality, and (b) is predictive of relevant political outcomes. Future research on the generalizability of the MFQr's psychometric structure is needed, but this refined measure offers the potential for acting as a springboard for the more psychometrically-rigorous assessment of the influence of core moral domains on political attitudes and behavior. 


\section{References}

Alper, S., \& Yilmaz, O. (2020). Does an abstract mind-set increase the internal consistency of moral attitudes and strengthen individualizing foundations? Social Psychological and Personality Science, 11, 326-335. https://doi.org/10.1177/1948550619856309.

Barnett, M. D., Öz, H. C. M., \& Marsden, A. D. (2018). Economic and social political ideology and homophobia: The mediating role of binding and individualizing moral foundations. Archives of Sexual Behavior, 47, 1183-1194. https://doi.org/10.1007/s10508017-0989-2.

Borsboom, D. (2008). Psychometric perspectives on diagnostic systems. Journal of Clinical Psychology, 64, 1089-1108. https://doi.org/10.1002/jclp.20503.

Borsboom, D., Cramer, A. O. J., Schmittmann, V. D., Epskamp, S., \& Waldorp, L. J. (2011). The small world of psychopathology. PLoS ONE, 6, e27407. https://doi.org/10.1371/journal.pone.0027407.

Boschloo, L., van Borkulo, C. D., Borsboom, D., \& Schoevers, R. A. (2016). A prospective study on how symptoms in a network predict the onset of depression. Psychotherapy and Psychosomatics, 85, 183-184. https://doi.org/10.1159/000442001.

Brandt, M. J., He, J., \& Bender, M. (2020). Registered report: Testing ideological asymmetries in measurement invariance. Assessment. [Article in press].

Chen, J., \& Chen, Z. (2008). Extended Bayesian information criteria for model selection with large model spaces. Biometrika, 95, 759-771. https://doi.org/10.1093/ biomet/asn034.

Christie, N. C., Hsu, E., Iskiwitch, C., Iyer, R., Graham, J., Schwartz, B., \& Monterosso, J. R. (2019). The moral foundations of needle exchange attitudes. Social Cognition, 37, 229246. https://10.1521/soco.2019.37.3.229.

Clifford, S. (2017). Individual differences in group loyalty predict partisan strength. Political Behavior, 39, 531-552. https://10.1007/s11109-016-9367-3.

Costantini, G., Richetin, J., Preti, E., Casini, E., Epskamp, S., \& Perugini, M. (2019).

Stability and variability of personality networks. A tutorial on recent developments in network psychometrics. Personality and Individual Differences, 136, 68-78. https://10.1016/j.paid.2017.06.011.

Cramer, A. O. J., Waldorp, L. J., van der Maas, H. L. J., \& Borsboom, D. (2010). Comorbidity: A network perspective. Behavioral and Brain Sciences, 33, 137-150. https://doi.org/10.1017/S0140525X09991567. 
Curry, O. S., Jones Chesters, M., \& Van Lissa, C. J. (2019). Mapping morality with a compass: Testing the theory of 'morality-as-cooperation' with a new questionnaire. Journal of Research in Personality, 78, 106-124. https://doi.org/10.1016/j.jrp.2018.10.008.

Cutts, D., Goodwin, M., Heath, O., \& Surridge, P. (2020). Brexit, the 2019 general election, and the realignment of British politics. The Political Quarterly, 91, 7-23. https://doi.org/10.1111/1467-923X.12815

Dalege, J., Borsboom, D., van Harreveld, F., \& van der Maas, H. L. (2017). Network analysis on attitudes: A brief tutorial. Social Psychological and Personality Science, 8, 528-537. https://doi.org/10.1177/1948550617709827.

Davis, D. E., Dooley, M. T., Hook, J. N., Choe, E., \& McElroy, S. E. (2017). The purity/sanctity subscale of the Moral Foundations Questionnaire does not work similarly for religious versus non-religious individuals. Psychology of Religion and Spirituality, 9 , 124-130. https://doi.org/10.1037/rel0000057.

Dickinson, J. L., McLeod, P., Bloomfield, R., \& Allred, S. (2016). Which moral foundations predict willingness to make lifestyle changes to avert climate change in the USA? PLoS ONE, 11, e0163852. https://doi.org/10.1371/journal.pone.0163852.

Doğruyol, B., Alper, S., \& Yilmaz, O. (2019). The five-factor model of the moral foundations theory is stable across WEIRD and non-WEIRD cultures. Personality and Individual Differences, 151, 109547. https://doi.org/10.1016/j.paid.2019.109547.

Duckitt, J., Bizumic, B., Krauss, S. W., \& Heled, E. (2010). A tripartite approach to rightwing authoritarianism: The authoritarianism- conservatism-traditionalism model. Political Psychology, 31, 685-715. https://doi.org/10.1111/j.1467-9221.2010. 00781.x.

Egorov, M., Kalshoven, K., Pircher Verdorfer, A., \& Peus, C. (2019). It's a match: Moralization and the effects of moral foundations congruence on ethical and unethical leadership perception. Journal of Business Ethics. Advance online publication. https://doi.org/10.1007/s10551-019-04178-9.

Epskamp, S. (2016). Regularized Gaussian psychological networks: Brief report on the performance of extended BIC model selection. Retrieved from http://arxiv.org/abs/ 1606.05771 .

Epskamp, S., Borsboom, D., \& Fried, E. I. (2018). Estimating psychological networks and their accuracy: A tutorial paper. Behavior Research Methods, 50, 195-212. https://doi.org/10.3758/s13428-017-0862-1. 
Epskamp, S., Cramer, A. O. J., Waldorp, L. J., Schmittmann, V. D., \& Borsboom, D. (2012). qgraph: Network visualizations of relationships in psychometric data. Journal of Statistical Software, 48, 1-18. https://doi.org/10.18637/jss.v048.i04.

Field, A. (2018). Discovering statistics using IBM SPSS statistics $\left(5^{\text {th }}\right.$ edition). London: SAGE.

Foygel, R., \& Drton, M. (2010). Extended Bayesian information criteria for Gaussian graphical models. Advances in Neural Information Processing Systems, 22, 2020-2028.

Franks, A. S., \& Scherr, K. C. (2015). Using moral foundations to predict voting behavior: Regression models from the 2012 U.S. presidential election. Analyses of Social Issues and Public Policy, 15, 213-232. https://doi.org/10.1111/asap.12074.

Friedman, J., Hastie, T., \& Tibshirani, R. (2008). Sparse inverse covariance estimation with the graphical lasso. Biostatistics, 9, 432-441. https://doi.org/10.1093/ biostatistics/kxm045.

Fruchterman, T. M. J., \& Reingold, E. M. (1991). Graph drawing by force-directed placement. Software: Practice and Experience, 21, 1129-1164. https://doi.org/10. 1002/spe.4380211102.

Graham, J., Haidt, J., Koleva, S., Motyl, M., Iyer, R., Wojcik, S. P., \& Ditto, P. H. (2013). Moral foundations theory: The pragmatic validity of moral pluralism. Advances in Experimental Social Psychology, 47, 55-130. https://doi.org/10.1016/B978-0-12-4072367.00002-4.

Graham, J., Haidt, J., \& Nosek, B. A. (2009). Liberals and conservatives rely on different sets of moral foundations. Journal of Personality and Social Psychology, 96, 1029-1046. https://doi.org/10.1037/a0015141.

Graham, J., Nosek, B. A., \& Haidt, J. (2012) The moral stereotypes of liberals and conservatives: Exaggeration of differences across the political spectrum. PLoS ONE, 7, e50092. https://doi.org/10.1371/journal.pone.0050092.

Graham, J., Nosek, B. A., Haidt, J., Iyer, R., Koleva, S., \& Ditto, P. H. (2011). Mapping the moral domain. Journal of Personality and Social Psychology, 101, 366-385. https://doi.org/10.1037/a0021847.

Gray, K., Schein, C., \& Ward, A. F. (2014). The myth of harmless wrongs in moral cognition: Automatic dyadic completion from sin to suffering. Journal of Experimental Psychology: General, 143, 1600-1615. https://doi.org/10.1037/a0036149.

Haidt, J. (2001). The emotional dog and its rational tail: A social intuitionist approach to moral judgment. Psychological Review, 108, 814-834. https://doi.org/10.1037//0033295X. 108.4.814. 
Haidt, J. (2012). The righteous mind: How good people are divided by politics and religion. London: Penguin.

Haidt, J., \& Graham, J. (2007). When morality opposes justice: Conservatives have moral intuitions that Liberals may not recognize. Social Justice Research, 20, 98-116. https://doi.org/10.1007/s11211-007-0034-z.

Haidt, J., \& Joseph, C. (2004). Intuitive ethics: How innately prepared intuitions generate culturally variable virtues. Daedalus, 133, 55-66. https://doi.org/10.1162/0011526042365555.

Harper, C. A., \& Harris, A. J. (2017). Applying moral foundations theory to understanding public views of sexual offending. Journal of Sexual Aggression, 23, 111-123. https://doi.org/13552600.2016.1217086.

Harper, C. A., \& Hogue, T. E. (2017, July 2). Ontological insecurity in political orientation and identification. Paper presented at the International Society of Political Psychology Annual Scientific Meeting. Edinburgh, Scotland.

Harper, C. A., \& Hogue, T. E. (2019). The role of intuitive moral foundations in Britain's vote on EU membership. Journal of Community and Applied Social Psychology, 29, 90103. https://doi.org/10.1002/casp.2386.

Hatemi, P. K., Crabtree, C., \& Smith, K. B. (2019). Ideology justifies morality: Political beliefs predict moral foundations. American Journal of Political Science, 63, 788-806. https://doi.org/10.1111/ajps.12448.

Hauser, D. J., \& Schwarz, N. (2016). Attentive Turkers: MTurk participants perform better on online attention checks than do subject pool participants. Behavior Research Methods, 48, 400-407. https://doi.org/10.3758/s13428-015-0578-z.

Hirsch, J. B., DeYoung, C. G., Xu, X., \& Peterson, J. B. (2010). Compassionate liberals and polite conservatives: Associations of agreeableness with political ideology and moral values. Personality and Social Psychology Bulletin, 36, 655-664. https://doi.org/10.1177/0146167210366854.

Iurino, K., \& Saucier, G. (2020). Testing measurement invariance of the Moral Foundations Questionnaire across 27 countries. Assessment, 27, 365-372. https://doi.org/10.1177/1073191118817916.

Iyer, R., Koleva, S., Graham, J., Ditto, P., \& Haidt, J. (2012). Understanding libertarian morality: The psychological dispositions of self-identified libertarians. Plos ONE. https://doi.org/10.1371/journal.pone.0042366.

JASP Team. (2020). JASP (Version 0.13.1). [Computer software]. 
Johnson, K. M., Iyer, R., Wojcik, S. P., Vaisey, S., Miles, A., Chu, V., \& Graham, J. (2017). Ideology-specific patterns of moral indifference predict intentions to vote. Analyses of Social Issues and Public Policy. Online only article. https://doi.org/10.1111/asap.12039.

Johnson, S. D., \& Tamney, J. B. (2001). Social traditionalism and economic conservatism: Two conservative political ideologies in the United States. The Journal of Social Psychology, 141, 233-243. https://doi.org/10.1080/00224540109600549.

Kim, K. R., Kang, J. -S., \& Yun, S. (2012). Moral intuitions and political orientation: Similarities and differences between South Korea and the United States. Psychological Reports, 111, 173-185. https://doi.org/10.2466/17.09.21.PR0.111.4.173-185.

Kivikangas, J. M., Lönnqvist, J. -E., \& Ravaja, N. (2017). Relationship of moral foundations to political liberalism-conservatism and left-right orientation in a Finnish representative sample. Social Psychology, 48, 246-251. https://doi.org/10.1027/1864-9335/a000297.

Kugler, M., Jost, J. T., \& Noorbaloochi, S. (2014). Another look at moral foundations theory: Do authoritarianism and social dominance orientation explain liberal-conservative differences in "moral” intuitions. Social Justice Research, 27, 413-431. https://doi.org/10.1007/s11211-014-0223-5.

Low, M., \& Wui, M. G. L. (2016). Moral foundations and attitudes towards the poor. Current Psychology, 35, 650-656. https://doi.org/10.1007/s12144-015-9333-y.

Malka, A., Osborne, D., Soto, C. J., Greaves, L. M., Sibley, C. G., \& Lelkes, Y. (2016). Binding moral foundations and the narrowing of ideological conflict to the traditional morality domain. Personality and Social Psychology Bulletin, 42, 1243-1257. https://doi.org/10.1177/0146167216653936.

McNally, R. J., Robinaugh, D. J., Wu, G. W. Y., Wang, L., Deserno, M. K., \& Borsboom, D. (2015). Mental disorders as causal systems: A network approach to posttraumatic stress disorder. Clinical Psychological Science, 3, 836-849. https://doi.org/10.1177/2167702614553230.

Milesi, P. (2017). Moral foundations and voting intention in Italy. Europe's Journal of Psychology, 13, 667-687. https://doi.org/10.5964/ejop.v13i4.1391.

Napier, J. L., \& Luguri, J. B. (2013). Moral mind-sets: Abstract thinking increases a preference for "individualizing" over "binding” moral foundations. Social Psychological and Personality Science, 4, 754-759. https://doi.org/10.1177/1948550612473783.

Nilsson, A., \& Erlandsson, A. (2015). The moral foundations taxonomy: Structural validity and relation to political ideology in Sweden. Personality and Individual Differences, 76, 28-32. https://doi.org/10.1016/j.paid.2014.11.049. 
O'Connor, B. P. (2000). SPSS and SAS programs for determining the number of components using parallel analysis and Velicer's MAP test. Behavior Research Methods, Instrumentation, and Computers, 32, 396-402. https://doi.org/10.3758/BF03200807.

Osborne, J. W., Costello, A. B., \& Kellow, J. T. (2008). Best practices in exploratory factor analysis. In J. Osborne (Ed.), Best practices in quantitative methods (pp. 86-101). Thousand Oaks: CA: Sage Publications.

Rempala, D. M., Okdie, B. M., \& Garvey, K. J. (2016). Articulating ideology: How liberals and conservatives justify political affiliations using morality-based explanations. Motivation and Emotion, 40, 703-719. https://doi.org/10.1007/s11031-016-9563-9.

Rosseel, Y., Jorgensen, T. D., Rockwood, N., Oberski, D., Byrnes, J., Vanbarbant, L., ..., \& Scharf, F. (2020). lavaan: Latent variable analysis. [R package]. Retrieved from https://cran.r-project.org/package=lavaan.

Smith, I. H., Aquino, K., Koleva, S., \& Graham, J. (2014). The moral ties that bind ... even to out-groups: The interactive effect of moral identity and the binding moral foundations. Psychological Science, 25, 1554-1562. https://doi.org/10.1177/0956797614534450.

Tibshirani, R. (1996). Regression shrinkage and selection via the lasso. Journal of the Royal Statistical Society: Series B (Methodological), 58, 267-288. https://doi.org/10.1111/j.25176161.1996.tb02080.x.

Tversky, A., \& Kahneman, D. (1974). Judgment under uncertainty: Heuristics and biases. Science, 185, 1124-1131. https://doi.org/10.1126/science.185.4157.1124.

Silver, J. R., \& Silver, E. (2017). Why are conservatives more punitive than liberals? A moral foundations approach. Law and Human Behavior, 41, 258-

272. https://doi.org/10.1037/lhb0000232.

van Borkulo, C. D., Boschloo, L., Borsboom, D., Penninx, B. W. J. H., Waldorp, L. J., \& Schoevers, R. A. (2015). Association of symptom network structure with the course of depression. JAMA Psychiatry, 72, 1219-1226. https://doi.org/10.1001/jamapsychiatry.2015.2079.

van de Leemput, I. A., Wichers, M., Cramer, A. O. J., Borsboom, D., Tuerlinckx, F., Kuppens, P., ..., \& Scheffer, M. (2014). Critical slowing down as early warning for the onset and termination of depression. Proceedings of the National Academy of Sciences of the United States of America, 111, 87-92. https://doi.org/10.1073/pnas.1312114110.

van der Maas, H. L. J., Dolan, C. V., Grasman, R. P. P. P., Wicherts, J. M., Huizenga, H. M., \& Raaijmakers, M. E. J. (2006). A dynamical model of general intelligence: The positive 
manifold of intelligence by mutualism. Psychological Review, 113, 842-861. https://doi.org/10.1037/0033-295X.113.4.842.

Vaughan, T. J., Holleran, L. B., \& Silver, J. R. (2019). Applying moral foundations theory to the explanation of capital jurors' sentencing decisions. Justice Quarterly, 36, 1176-1205. https://doi.org/10.1080/07418825.2018.1537400.

Voelkel, J. G., \& Brandt, M. J. (2019). The effect of ideological identification on the endorsement of moral values depends on the target group. Personality and Social Psychology Bulletin, 45, 851-863. https://doi.org/10.1177/0146167218798822.

Yilmaz, O., Harma, M., Bahçekapili, H. G., \& Cesur, S. (2016). Validation of the Moral Foundations Questionnaire in Turkey and its relation to cultural schemas of individualism and collectivism. Personality and Individual Differences, 99, 149-154. https://doi.org/10.1016/j.paid.2016.04.090. 